внутренних войск МВД России // Мир науки, культуры, образования. 2015. № 3 (52). С. 191-194.

16. Кашапов М.М. Психология педагогического мышления. СПб.: Алетейя, 2000. 463 с.

17. Кузьмина Н.В. Очерки психологии труда учителя // Новые исследования в педагогических науках. M., 1972. C. 9-12.

18. Педагогика и психология высшей школы: учебное пособие / под ред. М.В. Булановой-Топорковой. Ростов-на-Дону: Феникс, 2006. 512 с.

\section{TASK APPROACH TO INTRODUCING VALUES TO PROSPECTIVE LAWYERS}

(C) 2019

Vdovin Sergey Aleksandrovich, candidate of pedagogical sciences, deputy head Samara Law Institute of the Federal Penitentiary Service of Russia (Samara, Russian Federation)

Abstract. The paper is devoted to the problem of training a prospective lawyer who is able to build his professional activity on value grounds. The urgency of the problem of introducing values to prospective lawyers is argued from the position that the values of good, truth, justice, etc., becoming motives for the activities of a lawyer, ensure voluntary, free and informed fulfillment of moral requirements, which is an important condition for ensuring the security of individuals and the state. The content of the task approach to the introduction of values to prospective lawyers is revealed through the «task» concept content, and a problematic place occupies a special place. The «suprasituative level of problem detection» and the «situational level of problem detection» are considered in relation to the «task» concept. It is substantiated that the task approach orients the teacher to the introduction of values to prospective lawyers in the process of their involvement in solving problems of a supra-situational level in which they (prospective lawyers) find personal meaning. The author shows the effectiveness of personally-oriented tasks use for introducing values to prospective lawyers. It is shown that the penetration into the personal meaning of the task is possible both through its content and through the methods of its solution. An algorithm for solving a personally-oriented task is given: 1) an analysis of the situation of the lawyer professional activity; 2) formulation of the problem on the basis of the given situation; 3 ) analysis of the available means suitable for choosing ways of finding a solution to the problem; 4) action planning; 5) analysis of the results of their actions; 6) setting of new tasks. The author gives an example of how to use a personally-oriented task in the process of prospective lawyers' training.

Keywords: future lawyer; value; communion; an approach; task approach; task; personality-oriented task; humanitarian task; suprasituative level of problem detection; situational level of problem detection; algorithm for solving personally oriented tasks; reflection.

УДК 378.14

DOI 10.24411/2309-4370-2019-11305

Статья поступила в редакцию 10.05.2018

(C) 2019

Воронина Марина Анатольевна, старший преподаватель

кафедры иностранных языков и профессиональной коммуникации

Самарский национальный исследовательский университет имени академика С.П. Королёва

(2. Самара, Российская Федераичия)

Зубова Светлана Павловна, кандидат педагогических наук, доцент кафедры начального образования

Кочетова Наталья Геннадьевна, кандидат физико-математических наук, доцент, декан факультета начального образования

Самарский государственный соџиально-педагогический университет (2. Самара, Российская Федерация)

Аннотация. В данной статье рассматриваются актуальные вопросы подготовки будущих педагогов, в частности - формирования их профессиональной культуры. В составе профессиональной культуры педагогов выделяются пять компонентов. Ставится проблема развития ее поведенческо-рефлексивного компонента. Авторы проводят анализ федерального государственного образовательного стандарта высшего образования, кроме того, выделяют предпосылки развития поведенческо-рефлексивного компонента профессиональной культуры студентов - будущих педагогов. В статье авторами рассматриваются методики формирующего оценивания, как важный элемент профессиональной подготовки будущих педагогов. Анализируются стратегии формирующего оценивания, которые подразделяются на пять групп. Авторы статьи доказывают, что применение методик формирующего оценивания при подготовке будущих педагогов в процессе высшего образования способствует развитию поведенческо-рефлексивного компонента их профессиональной культуры. Анализ учебно-методической литературы позволил авторам статьи выделить методики формирующего оценивания, применяемые в процессе подготовки студентов - будущих педагогов. Выделенные авторами ме- 
тодики легли в основу разработанного учебно-методического комплекса дисциплины по выбору «Профессиональная культура педагога» по формированию профессиональной культуры будущих педагогов. В статье представлены результаты опытно-экспериментальной работы по развитию поведенческо-рефлексивного компонента профессиональной культуры студентов - будущих педагогов.

Ключевые слова: федеральный государственный образовательный стандарт высшего образования; профессиональная культура педагога; поведенческо-рефлексивный компонент профессиональной культуры будущих педагогов; методики формирующего оценивания; задания, направленные на развитие поведенческорефлексивного компонента профессиональной культуры педагога.

Первостепенной задачей современного образования в России является подготовка высококвалифицированных кадров, набор сформированных компетенций которых отвечал бы всем требованиям, предъявляемым современным обществом. Поиск путей и способов результативного обучения будущих специалистов становится актуальной темой для проведения исследований [1-6]. Таким образом, процесс профессионального образования становится одним из важнейших этапов в жизни человека.

Для успешного решения этой задачи обществу необходимы педагоги с высоким уровнем сформированности профессиональной культуры: обладающие системой целевых установок и ценностей, владеющие навыками применения средств, методов и технологий в педагогической деятельности, а также навыками организаторской деятельности.

Вопросами формирования профессиональной культуры занимались многие исследователи (И.М. Модель [7], В.Д. Шадриков и др. [8], А.П. Ситник [9], О.Г. Скворцова [10], А.М. Трудков [11], Р.Ф. Хайбуллина [12]). Анализ литературных источников показал, что исследователи выделяют в составе профессиональной культуры педагога различные составляющие, в некоторых случаях они перекликаются, хотя могут называться по-разному (система знаний и ценностей, средства и методы деятельности), в некоторых присутствуют дополнительные компоненты (мотивационный, эмоциональный, рефлексивный, коммуникативный). Нами были объединены все существующие мнения в единое интегративное понятие «профессиональная культура педагога», причем систему ценностей мы посчитали разумным объединить с мотивационной составляющей, поведенческие качества педагога с его рефлексией, особенности деятельности педагога отражены в информационно-методическом компоненте. При выделении компонентов особую роль уделили требованиям актуальных нормативных документов, регламентирующих образовательный процесс и добавили в компоненты культуры дополнительные составляющие элементы, такие как, например, знания основ первой медицинской помощи, безопасности жизнедеятельности и пр. Проведенное исследование позволило нам выделить и определить компоненты профессиональной культуры педагога (рис. 1).

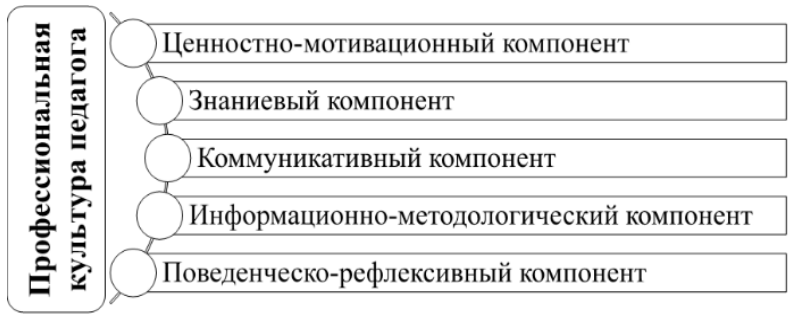

Рисунок 1 - Компоненты профессиональной культуры педагога
Отраженный состав свидетельствует о многоаспектности и многослойности выделенного понятия, что предполагает системный подход к формированию профессиональной культуры педагога.

Остановимся подробнее на развитии поведенческо-рефлексивного компонента профессиональной культуры педагога, который включает в себя:

- осознание социальной значимости педагогической профессии;

- осуществление профессиональной деятельности на проблемно-поисковой основе;

- гибкость и вариативность мышления;

- выполнение педагогических задач на творческой основе;

- регуляцию эмоций в кризисных ситуациях;

- построение позитивных отношений с окружающими: коллегами, родителями, обучающимися;

- навыки целеполагания и планирования педагогической деятельности;

- профессиональную мобильность;

- навыки оценивания своей деятельности;

- владение методами педагогической рефлексии;

- навыки саморегуляции, самоконтроля, самоанализа,

- навыки коррекции, осуществляемой на основе проведенного анализа.

Исследования (Е.Н. Землянская [13], Е.П. Круподерова [14], Т.В. Четвертных [15]) показывают, что применение на занятиях методик формирующего оценивания с использованием информационно-коммуникационных технологий способствует развитию вышеотмеченных элементов поведенческо-рефлексивного компонента профессиональной культуры педагога.

Формирующее оценивание - это оценивание учебно-воспитательного процесса, когда анализируются ценностные установки, знания, умения, в том числе рефлексивные, устанавливается обратная связь об успехах и недостатках обучающегося. Формирующее оценивание призвано определить недостатки в сформированности у студентов компетенций с целью дальнейшего максимально-эффективного их устранения. Формирующее оценивание - непрерывная взаимная работа педагога и студента, а также внесение корректив в их деятельность с целью улучшения процесса обучения. Преподаватель помогает обучающемуся научиться объективно оценивать себя и применять полученную таким образом информацию для улучшения собственных результатов. Студент начинает понимать, что чем активнее он участвует в собственном обучении, тем выше могут быть его результаты обучения.

Что касается педагогических целей использования стратегий формирующего оценивания, то среди доминирующих можно отметить следующие:

- оценить уровень образовательных достижений студентов, их мотивационную, содержательную и 
технологическую готовность к профессиональной деятельности;

- стимулировать развитие самостоятельности и сотрудничества;

- сделать процесс обучения прозрачным и выявить динамику образовательных достижений с целью коррекции деятельности и повышения её результативности.

Оценивание в процессе образования должно быть спланировано таким образом, чтобы:

- использовались различные стратегии, методы и средства оценивания;

- оценивание использовалось в процессе всего периода обучения;

- обучающиеся вовлекались в процессы оценивания.

Авторами (О.Ф. Брыксиной [16], М.А. Пинской [17] и др.) были классифицированы современные методики формирующего оценивания. Рассмотрим их применение в качестве инструмента развития поведенческо-рефлексивного компонента.

1. Стратегии для определения потребностей обучающихся.

Несомненно, эффективность процесса образования зависит от сформированного в школе набора компетенций, психологических и эмоциональных качеств, с которыми студент приходит в вуз. Обладая знаниями об этих показателях с самого начала, педагог может изменять привычный ход образовательной траектории, подстраивая ее под вновь открывшиеся факты.

Очень важно процедуру выявления потребностей, базового опыта и динамику их приращений сделать прозрачной, поскольку образовательные достижения участников образовательного процесса важно видеть не только преподавателю, но и самим обучающимся. И осознание приобретенных знаний, полученного опыта работы с информацией, планирования и организации деятельности, взаимодействия с участниками и т.п. зачастую является очень мощным стимулом к активизации деятельности.

Наиболее эффективными инструментами стратегии выявления потребностей обучающихся являются графические планировщики (например, таблица «Знаю - Интересуюсь - Уже научился»), карты знаний, анкеты и т.п., которые позволяют соотнести потребности и полученный опыт.

2. Стратегии развития самостоятельности и взаимодействия.

Актуальность применения данной стратегии формирующего оценивания объясняется, прежде всего, требованиями Федерального государственного образовательного стандарта высшего образования (ФГОС BO) по направлению подготовки Педагогическое образование к образовательным результатам обучающихся, которые включают способность к самоорганизации и самообразованию, готовность к разработке направления своего профессионального роста и личностного развития, толерантность [18].

Несомненно, этапы планирования и реализации плана предполагают активное взаимодействие обучающихся, делегирование ответственности и координацию деятельности всех, особенно если говорить о групповой работе.

Не менее важным навыком является готовность осуществлять контроль своей деятельности в про- цессе достижения результата, корректировать свои действия в соответствии с изменяющейся ситуацией. Одним из эффективных способов для формирования вышеуказанных компетенций является разработка инструментов для самооценивания. При этом серьезное внимание должно уделяться критериальному подходу к оцениванию результатов учебной деятельности.

3. Стратегии наблюдения за процессом.

В течение всего образовательного процесса педагогу необходимо обеспечивать объективную и конструктивную обратную связь.

Методики стратегии наблюдения за процессом могут носить как неформальный характер (например, непосредственное наблюдение, встречи, беседы), так и регламентированный (отчеты, оценочные листы и т.п.). Необходимо отметить особую эффективность инструментов, носящих формализованный характер и направленных на рефлексию обучающихся и самодиагностику, при этом сами инструменты должны быть прозрачны и понятны.

4. Стратегии проверки понимания.

В плане выявления уровня понимания проблемы обучающимися крайне эффективными являются различные техники визуализации (кластеры, ментальные карты, ленты времени, «фиш-боун» и т.п.).

В процессе разработки таких информационных продуктов обучающиеся демонстрируют понимание проблемы: причины ее возникновения, ключевые факты, определяющие ее порождение и влияющие на ее решение. А выбранная графическая техника позволяет не только визуализировать совокупность этих фактов, отразить их иерархическую природу, но и является ключевым аспектом выявления причинноследственных связей. Не менее важными инструментами выявления уровня погружения в предметное поле являются «бортовые журналы», эссе, «цифровые истории», блоги и т.п.

5. Стратегии, доказывающие понимание и умения.

Как правило, реализация данной стратегии оценивания связана с оценкой результатов деятельности студентов или представлением и анализом портфолио, демонстрирующим прогресс и достижения обучающегося. Этот этап является квинтэссенцией проделанной работы в вузе.

Таким образом, методики формирующего оценивания являются перспективным инструментом развития элементов поведенческо-рефлексивного компонента профессиональной культуры педагога.

В ходе исследования нами был разработан учебно-методический комплекс (УМК) дисциплины по выбору «Профессиональная культура педагога» по формированию профессиональной культуры студентов будущих педагогов покомпонентно и в целом. Рассмотрим подробнее задания, предлагаемые студентам для развития поведенческо-рефлексивного компонента профессиональной культуры педагога.

При составлении заданий мы использовали методики формирующего оценивания, способствующие развитию элементов поведенческо-рефлексивного компонента профессиональной культуры педагога, которые выполнялись студентами в облачных технологиях. 
Хотим отметить, что каждое задание сопровождается обсуждением работы группы. Перед выполнением каждого задания преподаватель организовывает работу по планированию деятельности, обсуждая с группой, как конструктивнее выполнить то или иное задание. После выполнения задания преподаватель организует работу по рефлексии, обсуждая со студентами, что было для них легким и что сложным. Задает наводящие вопросы так, чтобы обучающиеся сами приняли решение, как справиться с возникшими сложностями, и оценили результаты.

Кроме того, перед изучением каждой темы предлагаем начать заполнять каждому студенту таблицу «Знаю - Интересуюсь - Уже научился» (табл. 1).

Таблица 1 - Методика «Знаю - Интересуюсь Уже научился»

\begin{tabular}{|c|c|c|c|}
\hline $\begin{array}{c}\text { Изучаемая } \\
\text { тема }\end{array}$ & Знаю & Интересуюсь & $\begin{array}{c}\text { Уже } \\
\text { научился }\end{array}$ \\
\hline & & & \\
\hline & & & \\
\hline
\end{tabular}

В самом начале студенты в графе «Изучаемая тема» заполняют подтемы, которые будет проходить группа, каждый обучающийся отмечает столбцы «Знаю» и «Интересуюсь». После изучения темы и ее подтем каждый студент заполняет столбец «Уже научился», при этом важно организовать обсуждение успехов и неудач, а также возможных причин, способов преодоления затруднений.

Кроме того, каждый обучающийся заполнял список «Мои приоритеты» (рис. 2), отмечая наиболее важные изученные темы, добавляя темы, которые интересуют его самого.

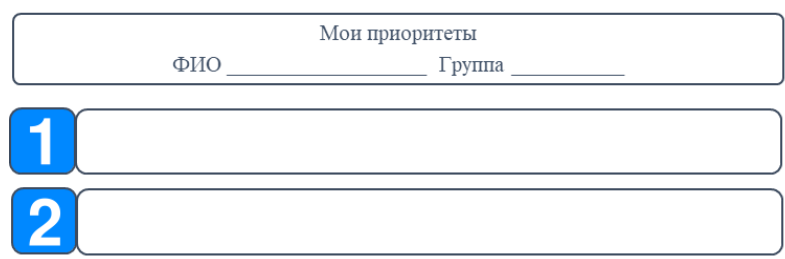

Рисунок 2 - Методика «Мои приоритеты»

В процессе работы над темой каждый студент также заполнял «Личный дневник обучающегося» (табл. 2), это способствовало планированию деятельности, выделению ее целей, следованию планам и самооцениванию.

Таблица 2 - Методика «Личный дневник обучающегося»

\begin{tabular}{|c|c|c|c|c|c|}
\hline & $\begin{array}{r}\text { ФИ } \\
\text { Груп }\end{array}$ & $\begin{array}{l}\text { ІиЧНЫЙ } \\
\text { О } \\
\text { та }\end{array}$ & ДНЕВН & & \\
\hline Дата & $\begin{array}{c}\text { Что } \\
\text { необхо- } \\
\text { димо } \\
\text { сделать? }\end{array}$ & $\begin{array}{c}\text { Какие } \\
\text { ресурсы } \\
\text { необхо- } \\
\text { димы? }\end{array}$ & $\begin{array}{c}\text { Что } \\
\text { сдела- } \\
\text { но? }\end{array}$ & $\begin{array}{c}\text { Воз- } \\
\text { ник- } \\
\text { шие } \\
\text { труд- } \\
\text { ности? }\end{array}$ & $\begin{array}{c}\text { Причи- } \\
\text { ны воз- } \\
\text { никно- } \\
\text { вения } \\
\text { трудно- } \\
\text { стей? }\end{array}$ \\
\hline & & & & & \\
\hline & & & & & \\
\hline
\end{tabular}

Примеры заданий, выполняемых студентами:

1) Создайте систему оценивания серии разработанных вами уроков.

2) Разработайте критерии оценивания созданного вами для обучающихся образовательного квеста.

3) Разработайте личный педагогический сайт.

Кроме того, помимо использования методик формирующего оценивания, перед началом выполнения заданий студентам предлагалось обсудить критерии его оценивания, что также способствует формированию навыков планирования, а впоследствии - оценивания и корректировки своей деятельности. Таким образом, в процессе выполнения обозначенных заданий у студентов - будущих педагогов формируются выделенные элементы поведенческорефлексивного компонента их профессиональной культуры.

Для подтверждения эффективности разработанного УМК нами была проведена опытно-экспериментальная работа, которая включала три этапа констатирующий, формирующий и контрольный.

В ходе констатирующего этапа была проведена первичная диагностика поведенческо-рефлексивного компонента профессиональной культуры студентов будущих педагогов с использованием следующих методик:

- методика определения стрессоустойчивости и социальной адаптации [19];

- методика диагностики уровня развития рефлексивности [20].

Целью формирующего этапа эксперимента была апробация разработанного УМК: студентам экспериментальной группы (25 чел.) предлагались задания из разработанного УМК, студенты контрольной группы (24 чел.) обучались по стандартной программе.

По завершении формирующего этапа был проведен контрольный эксперимент по выявлению уровня сформированности поведенческо-рефлексивного компонента профессиональной культуры студентов будущих педагогов с помощью тех же методик, что и в процессе констатирующего этапа. Сравнительные результаты представлены на рис. 3 и рис. 4.

Данные диаграммы (рис. 3) показывают, что в результате эксперимента у студентов экспериментальной группы значительно возрос уровень сформированности стрессоустойчивости и социальной адаптации, количество студентов контрольной группы с низким уровнем более чем в 2 раза превышает количество студентов с таким же уровнем сформированности стрессоустойчивости и социальной адаптации в экспериментальной группе.

Из диаграммы (рис. 4) видно, что по результатам контрольного эксперимента студенты экспериментальной группы превышают студентов контрольной группы по уровню развития рефлексивности.

Таким образом, результаты опытно-экспериментальной работы доказывают эффективность использования методик формирующего оценивания в вузе. Применение обозначенных методик способствует развитию элементов поведенческо-рефлексивного компонента профессиональной культуры студентов будущих педагогов. 


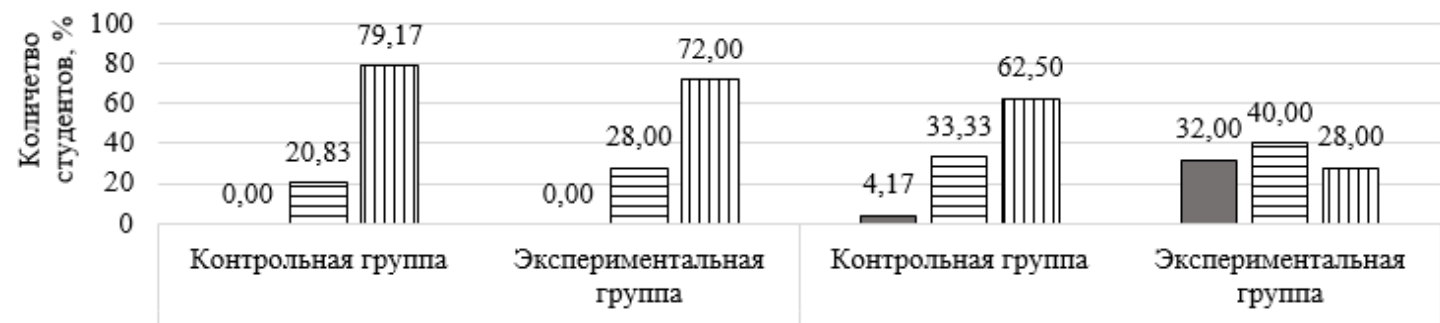

Констатирующий эксперимент

Контрольный экспернмент

口Высокий

Рисунок 3 - Уровни сформированности стрессоустойчивости и социальной адаптации студентов

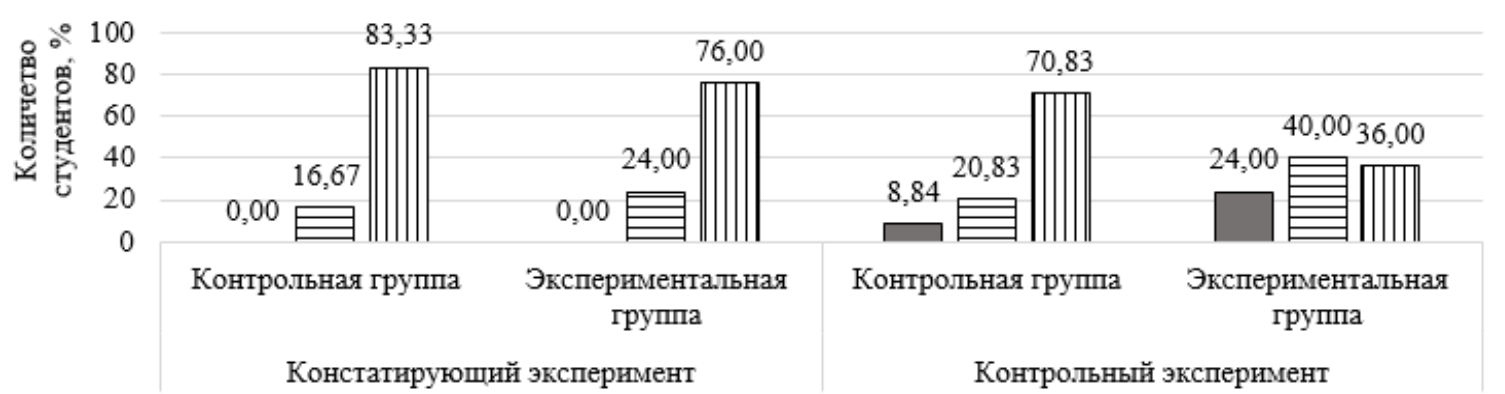

Констатирующий эксперимент

Контрольный эксперимент

\section{Рисунок 4 - Уровни развития рефлексивности студентов}

\section{Список литературы:}

1. Агрикова Е.В. Формирование навыков трансмедийного повествования у студентов - будущих журналистов средствами иностранного языка // Общество: социология, психология, педагогика. 2016. № 8. С. 91-94.

2. Брыксина О.Ф. ИКТ-навыки студентов как условие формирования универсальных компетенций // Нефтегазовый комплекс: проблемы и инновации: тез. II науч.-практ. конф. с междунар. участием / отв. ред. В.К. Тян. Самара: Самар. гос. техн. ун-т, 2018. С. 172.

3. Кочетова Т.Н. Особенности современной математической подготовки будущего инженера // Coвременные технологии подготовки кадров и повышения квалификации специалистов нефтегазового производства: тезисы междунар. науч.-практ. конф. / отв. ред. В.К. Тян. Самара: Самар. гос. техн. ун-т, 2014. С. 51.

4. Сорокина Т.О., Левченко В.В. Формирования навыков свободного общения на английском языке у взрослых на основе применения информационных технологий // Иноязычное образование в поликультурной среде: мат-лы и доклады XXIV науч.-практ. конф. Национальной ассоциации преподавателей английского языка (NATE 2018) (Самара, 18-20 апреля 2018 г.) / отв. ред. В.В. Левченко. Самара: Изд-во Самарского университета, 2018. С. 366-372.

5. Лукьянова М.И., Шустова Л.П., Данилов С.В. Развитие компетентности педагогов в контексте реализации современных научных подходов в инновационной деятельности образовательных организаций // Известия Саратовского университета. Новая серия. Акмеология образования. Психология развития. 2018. № 2 (Т. 7). С. 102-109.

6. Стельмах Я.Г., Кочетова Т.Н. Вектор организации самостоятельной работы студентов технического вуза // Азимут научных исследований: педагогика и психология. 2016. Т. 5, № 4 (17). С. 246-249.
7. Модель И.М. Профессиональная культура (общесоциологический аспект): автореф. дис. ... канд. социол. наук: 22.00.08. Свердловск, 1983. 18 с.

8. Профессионализм современного педагога: методика оценки уровня квалификации педагогических работников / под науч. ред. В.Д. Шадрикова. М.: Логос, $2011.168 \mathrm{c}$

9. Ситник А.П. Профессиональная культура учителя: исторические аспекты проблемы // Школа. 1998. № 1. С. 3-40.

10. Скворцова О.Г. Профессиональная культура преподавателя вуза в социологическом измерении // Актуальные проблемы гуманитарных и естественных наук. 2015. № 12-7. С. 114-119.

11. Трудков А.М. Профессиональная культура учителя музыки. Мурманск, 2005. 138 с.

12. Хайбуллина Р.Ф. Формирование профессиональной культуры будущих учителей музыки в процессе инструментально-исполнительской подготовки: дис. ... канд. пед. наук: 13.00.08. Уфа, 2016 204 c.

13. Землянская Е.Н. Формирующее оценивание (оценка для обучения) образовательных достижений обучающихся // Современная зарубежная психология. 2016. № 3. С. 50-58.

14. Канянина Т.И., Круподерова Е.П. Использование ИКТ-инструментов для формирующего оценивания // Наука и образование в XXI веке: сборник научных трудов по материалам междунар. науч.практ. конф. Люберцы: ООО «АР-Консалт», 2017. C. 101-103.

15. Четвертных Т.В. Формирующее оценивание и его влияние на личностные образовательные результаты обучающихся // Вестник Оренбургского государственного педагогического университета. 2018 № 2 (26). С. 304-312.

16. Брыксина О.Ф., Круподерова Е.П. Оценивание результатов проектной деятельности учащихся // 
Современные исследования социальных проблем. ской Федерации от 04.12.2015 г. № 1426 [Электрон2015. № 1 (21). С. 223-228.

17. Пинская М.А. Формирующее оценивание: оценивание в классе: учеб. пособие. М.: Логос, 2010. $264 \mathrm{c}$.

18. Федеральный государственный образовательный стандарт высшего образования. Уровень высшего образования - бакалавриат. Направление подготовки 44.03.01 Педагогическое образование. Утв. приказом Министерства образования и науки Российный ресурс] // Портал Федеральных государственных образовательных стандартов высшего образования. http://fgosvo.ru/uploadfiles/fgosvob/440301.pdf.

19. Практическая психодиагностика. Методики и тесты: учебное пособие / под ред. Д.Я. Райгородского. Самара: Бахрах-М, 2001. 672 с.

20. Карпов А.В. Психология рефлексивных механизмов деятельности. М.: Институт психологии РАН, 2004. $424 \mathrm{c}$.

\title{
FORMATIVE ASSESSMENT TECHNIQUES AS A TOOL FOR THE DEVELOPMENT OF THE BEHAVIORAL-REFLEXIVE COMPONENT OF THE FUTURE TEACHER'S PROFESSIONAL CULTURE
}

(C) 2019

Voronina Marina Anatolyevna, senior lecturer of Modern Languages and Professional Communication Department Samara National Research University (Samara, Russian Federation)

Zubova Svetlana Pavlovna, candidate of pedagogical sciences, associate professor of Primary Education Department

Kochetova Natalia Gennadyevna, candidate of physical and mathematical sciences, associate professor, head of Primary Education Faculty

Samara State University of Social Sciences and Education (Samara, Russian Federation)

Abstract. This paper discusses current issues of future teachers' training, in particular their professional culture development. There are five components in the teachers' professional culture. The problem of its behavioralreflexive component development is posed. The authors analyze the federal state educational standard of higher education as well as highlight prerequisites for the development of the behavioral-reflective component of future teachers' professional culture. The paper considers techniques of formative assessment as an important element of future teachers' professional training. Formative assessment strategies are analyzed; they are divided into five groups. The authors argue that the use of formative assessment techniques for future teachers' training at universities contributes to the development of the behavioral-reflexive component of their professional culture. The analysis of educational and methodical literature allowed the authors to single out the techniques of formative assessment used in the process of future teachers' training. The methodologies identified by the authors formed the basis of the developed educational-methodical complex of the course «Professional culture of the teacher» aimed at future teachers' professional culture development. The paper presents the results of the experiment aimed at development of the behavioralreflexive component of future teachers' professional culture.

Keywords: federal state educational standard of higher education; professional culture of teacher; behavioralreflective component of future teachers' professional culture; techniques of formative assessment; tasks aimed at development of behavioral-reflexive component of teacher's professional culture.

УДК 37.013 .75

DOI 10.24411/2309-4370-2019-11306

Статья поступила в редакцию 05.01.2019

\section{ПРЕДПОСЫЛКИ И ПЕРСПЕКТИВЫ РАЗВИТИЯ ЗДОРОВЬЕСБЕРЕГАЮЩЕЙ ПЕДАГОГИКИ В МУРМАНСКОЙ ОБЛАСТИ}

(C) 2019

\author{
Киевская Ольга Геннадьевна, кандидат педагогических наук, профессор, \\ декан факультета естествознания, физической культуры и безопасности жизнедеятельности \\ Ерохова Наталья Валерьевна, кандидат педагогических наук, доцент, \\ заведующий кафедрой физической культуры, спорта и безопасности жизнедеятельности \\ Мурманский арктический государственный университет (2. Мурманск, Российская Федерация)
}

Аннотация. В статье кратко представлен анализ формирования у студентов Мурманского арктического
государственного университета таких компетенций: готовность поддерживать уровень физической подго-
товки, обеспечивающий полноценную деятельность, и готовность к обеспечению охраны жизни и здоровья
обучающихся в рамках реализации Федерального государственного образовательного стандарта высшего
образования. На основе педагогических исследований, проведённых среди студентов Мурманского арктиче-
ского государственного университета, показаны предпосылки и перспективы здоровьесберегаюей педаго-
гики в Мурманской области, обозначены приоритеты развития Центра здоровьесбережения, открытого на
базе вуза, разработаны организационно-педагогические рекомендации по оптимизации образовательного
процесса, ориентированного на физическую культуру, сохранение и укрепление здоровья обучающихся с
учётом климатогеографических особенностей региона. Выявилась следующая тенденция: внедрение в учеб-
ный процесс по физической культуре индивидуально-дифференцированного подхода, учитывающего кон-
ституцию обучающихся, показали ее эффективность по сравнению с другими подходами в физической под- 